\title{
El Pueblo de los idiomas (das Sprachdorf): un recurso metodológico basado en realia para desarrollar la competencia comunicativa ${ }^{1}$
}

\author{
TOMÁs CóRColes Molina \\ Universitat de València \\ tomas.corcoles@uv.es
}

\begin{abstract}
Resumen: En este artículo se presenta un recurso metodológico conocido en alemán como Sprachdorf que permite desarrollar la competencia comunicativa de nuestros alumnos a través de interacciones orales contextualizadas e integrar el aprendizaje de contenidos léxicos, gramaticales, pragmáticos y culturales. Este tipo de proyecto se está llevando a cabo en Alemania y Países Bajos, pero posee una larga tradición desde finales del siglo XIX basada en el concepto de realia. Su implementación en centros de secundaria puede solucionar el problema de falta de prácticas orales y ayudar a ofrecer una visión significativa de la adquisición de lenguas extranjeras.
\end{abstract}

Palabras clave: realia, competencia comunicativa, ASL, interacción oral, contexto, aprendizaje significativo, aprendizaje cooperativo

\begin{abstract}
This paper introduces a methodological resource known as Sprachdorf in German, which allows students to develop their communicative competence through contextualized oral interactions and to integrate lexical, grammatical, pragmatic and cultural contents. This kind of project is being carried out in Germany and The Netherlands, but it finds its roots at the end of the nineteenth century based on the concept of realia. If Sprachdorf is implemented in secondary schools, it could provide a solution for the lack of oral exercises in class and a meaningful perspective of secondlanguage acquisition.
\end{abstract}

Keywords: realia, communicative competence, SLA, oral interaction, context, meaningful learning, cooperative learning

\section{Introducción}

El recurso metodológico que presentamos en este artículo recibe en alemán el nombre de Sprachdorf, palabra compuesta por la voz Sprach-, procedente de Sprache, que significa «lengua, idioma», y Dorf, «pueblo o aldea» ${ }^{2}$. En holandés existe la voz similar Taaldorp;

\footnotetext{
${ }^{1}$ Este artículo ha sido posible gracias al proyecto de investigación FFI2016-77842-P, Unidades discursivas para una descripción sistemática de los marcadores del discurso en español (UDEMADIS), financiado por el MINECO, la AEI y los fondos FEDER

${ }^{2}$ El término puede ser también una traducción de la voz Language Villages, el nombre de los programas de inmersión lingüística que ofrece Concordia College, una universidad privada de Minnesota, en Estados Unidos. Estos programas consisten en campamentos de verano e invierno en diferentes lugares de dicha ciudad, donde los estudiantes aprenden idiomas a través de una adaptación total a una vida en esa segunda lengua -comen, hablan, juegan o realizan actividades en esa lengua-. Lo más llamativo de estas experiencias es que las instalaciones de estos cursos se erigen en «pueblos», que pese a su construcción $a d$ $h o c$, poseen un gran carácter de veracidad para provocar esa sensación total de inmersión en la cultura y en
} 
sin embargo, en español no hemos encontrado ninguna propuesta previa de traducción, por lo que creemos que una denominación inicial podría ser Pueblo de los idiomas; no obstante, también podría llamarse Aula de los idiomas, ya que se trata de un recurso ubicado en un centro educativo.

Este Pueblo o Aula de los idiomas consiste en un espacio físico del centro escolar en el que se encuentran «escenarios de interacción», tales como un restaurante, un mercado o una tienda de ropa, entre otros. Estos «rincones de trabajo» son reales, es decir, cuentan con objetos verosímiles, como frutas de plástico, platos, vasos y cubiertos o prendas de ropa. En ellos pueden plantearse actividades de interacción oral, como la creación de situaciones comunicativas que se encuentran en contextos concretos, más o menos similares a los que existen en la vida real. Todo esto permitirá a nuestros alumnos desarrollar una competencia clave en las asignaturas de idiomas: la competencia comunicativa. Más allá de servir como tarea final de una unidad didáctica, este recurso ofrece una metodología que permite secuenciar el aprendizaje de contenidos léxicos, gramaticales, pragmáticos y culturales, gracias a lo cual, puede integrarse fácilmente en las programaciones anuales de las asignaturas.

\subsection{Razones para su existencia}

La creación de un recurso como este viene motivada por varios factores: en primer lugar, dadas las circunstancias actuales en la enseñanza secundaria, no solo en España, sino en la mayoría de los países europeos, la ratio de alumnos es muy elevada, y si nos centramos en la duración de las clases, encontramos que hay escasas oportunidades de interacción oral en la lengua extranjera (en adelante, L2) que faciliten la participación de todos.

En segundo lugar, si realizamos una panorámica de las actividades orales propuestas en los manuales, nos daremos cuenta de dos problemas fundamentales: su carácter ficticio e irreal y la escasa contextualización que presentan (Brosig, 2019). Por consiguiente, los estudiantes, ya sea por desmotivación u otros factores personales, tales como la timidez o la falta de disposición a comunicarse, tanto si disponen de buenas aptitudes lingüísticas, como si no, no logran apreciar la utilidad de expresarse en otra lengua diferente a la materna, sobre todo para hablar de temas que no les interesan.

En tercer lugar, y como consecuencia de lo expuesto, el nivel de muchos de los alumnos respecto a las destrezas orales en L2 es todavía muy mejorable; de hecho, se ha demostrado que tantos los profesores como los estudiantes de ELE consideran que «la expresión y la interacción oral son las destrezas que requieren un mayor número de prácticas, y para los alumnos, más concretamente, la fluidez, la expresión y la interacción oral son las destrezas que desean perfeccionar» (Cordeiro, 2018: 521).

En el presente artículo detallaremos algunos aspectos importantes que se han de conocer para poder llevar a cabo este proyecto: en primer lugar, explicaremos de qué bases metodológicas parte esta idea (§ 2) y ofreceremos los ejemplos que actualmente se desarrollan (§ 3). En segundo lugar, nos centraremos en nuestras experiencias prácticas, desde el modo de preparación de este recurso ( $(4)$, la metodología que implica (§ 5), las posibles actividades que pueden realizarse $(\S 5.3)$ y los resultados que hemos extraído $(\S$ $6)$. Por último, expondremos unas reflexiones finales a modo de conclusión ( $§ 7)$, las referencias bibliográficas y un breve anexo.

la lengua meta. Para obtener más información, consúltese la página web de la organización: http://www.concordialanguagevillages.org/ 


\section{Bases metodológicas}

\subsection{Realia como tradición metodológica}

El Sprachdorf se enmarca en una larga tradición metodológica conocida como realia. Una de las primeras definiciones del concepto aparece a finales del siglo XIX, en un libro titulado The method of teaching modern languages in Germany:

The Word Realien (real things or realities) is somewhat vague and comprehensive. It covers everything that is illustrative of a nation's real life and thought -its literature, history and geography, its institutions, manners and customs $[\ldots]$

(Brebner 1898:32)

Los trabajos sobre realia se desarrollan en Norteamérica, a lo largo de la primera mitad del siglo XX, por profesores de idiomas en educación secundaria, que publican en revistas como The Modern Language Journal (Cru et al., 1929; Milone, 1937; Spurr, 1942; Held, 1938). Estos trabajos reflexionan sobre la necesidad de fomentar un aprendizaje auténtico y destacan la utilidad de recursos como periódicos y revistas, enciclopedias, postales, monedas u obras de arte, que han de ser originales y proceder del país origen, dado que con ellos se puede desarrollar una cultura verdadera de aprecio y tolerancia hacia la L2 (Held, 1938).

Gobert (2018) opina que los realia fomentan un aprendizaje mucho más atractivo para el alumno porque el discurso que se crea en actividades como «role plays» se parece más al habla espontánea y coloquial si lo comparamos con otro tipo de ejercicios orales, como las simples entrevistas en parejas sobre sus gustos o preocupaciones.

En un sentido más amplio, la noción de realia puede entenderse no solo como materiales procedentes de la comunidad hablante, sino como el uso de «objetos de cualquier origen que son utilizados para ilustrar vocabulario y estructuras en L2» (Celce-Murcia y Hilles, 1988, en Álvarez, 2011: 13). Es decir, cualquier recurso que pueda estimular el interés del alumno por la lengua extranjera y su cultura, en la medida en que ofrezcan un carácter de verosimilitud en la (re)creación de ambientes y contextos.

\subsection{Realia en la etapa de Educación Infantil}

Los estudios sobre didáctica en Educación Infantil de 0 a 6 años sí que han dedicado una atención particular a este concepto, ya que se utilizan recursos similares al Pueblo de los Idiomas, como «rincones de clase» (Lleixà, 2001) o los «rincones de juego simbólico o talleres» (Bassedas et al., 2000; Bigas y Correig, 2001), que se conciben como espacios ubicados dentro del aula: «la tienda de frutas de plástico, de yogures, de botellines, el restaurante con fichas o chapas que representen el dinero» (Lleixà, 2001: 77), o las «casas de muñecas, peluquerías o enfermerías[,] donde los niños pueden recrear experiencias cotidianas» (Bassedas et al., 2000: 177).

Dentro de estos rincones se realizan «juegos dramáticos o de roles» en los que el alumno deja de ser él mismo y asumen un rol diferente al del habitual, lo cual fomenta una empatía hacia los sentimientos de otras personas y se produce una globalización educativa por

\footnotetext{
${ }^{3}$ La palabra Realia (cosas reales o realidades) es en cierto modo ambigua y al mismo tiempo transparente. Abarca todo lo que es ilustrativo del auténtico modo de vida y pensamiento de una nación -su literatura, historia y geografia, sus instituciones, maneras de ser y costumbres [...] (Brebner 1898:32, traducción nuestra).
} 
diferentes modalidades expresivas (oral, gestual, sonora, musical, motriz), lo que potencia la creatividad del individuo (Bassedas et al., 2000).

Los profesionales educadores parten de varias premisas básicas: comunicación, interacción con el medio y juego. En primer lugar, uno de los objetivos principales de la educación con respecto a la competencia comunicativa es «favorecer el desarrollo del lenguaje en los diversos usos y funciones que puede realizar» (Lleixà, 2001: 91) a través del establecimiento de vínculos afectivos como los que se han creado el ámbito familiar.

En segundo lugar, otro propósito esencial es que los niños realicen actividades motrices donde toquen e interactúen con los objetos; esto constituirá las bases, por un lado, del pensamiento inteligente y, por otro, a nivel afectivo, de su autonomía y su autoconfianza (Lleixà, 2001: 22).

En tercer lugar, se han de incentivar las actividades lúdicas, ya que estas forman parte indispensable del aprendizaje de los infantes. El juego está considerado un instrumento que posee un gran potencial didáctico, ya que cuando se juega con otros, se aprende a expresarse y a comunicarse socialmente. La misión de los docentes es fomentar que los niños manipulen diferentes materiales y objetos, que imaginen diferentes historias y situaciones y las verbalicen junto con sus compañeros, para que se produzca un intercambio y un enriquecimiento mutuo.

\subsection{Realia desde un triple enfoque: comunicativo, significativo y cooperativo}

El Marco Común Europeo de Referencia para las Lenguas (MCER) (2002) defiende un concepto de aprendizaje de la lengua, basado en el enfoque comunicativo, que

se centra en la acción en la medida en que considera a los usuarios y alumnos que aprenden una lengua principalmente como agentes sociales, es decir, como miembros de una sociedad que tiene tareas (no sólo relacionadas con la lengua) que llevar a cabo en una serie determinada de circunstancias, en un entorno específico y dentro de un campo de acción concreto (p. 9) ${ }^{4}$

Por tanto, para realizar dichas tareas con éxito como individuos sociales, necesitamos desarrollar y utilizar estratégicamente una serie de competencias generales, dentro de las cuales se encuentra la competencia comunicativa, subdividida a su vez en competencias lingüísticas, sociolingüísticas y pragmáticas.

El Plan Curricular del Cervantes (2006) y el MCER actualizado con nuevos descriptores (2018) aportan de forma más detallada las situaciones comunicativas de la vida real en las que alumnos deberán desenvolverse. Por ejemplo, en este último, en el apartado 4.4.3, Estrategias de interacción, y concretamente, estrategias para obtener bienes y servicios, en el nivel A2, se señalan que algunas habilidades han de ser estas: Pregunta sobre cosas y realiza transacciones sencillas en tiendas, oficinas de correo o bancos; Sabe cómo pedir comida en un restaurante o Sabe pedir (cara a cara) una cita médica y entender la respuesta. Sabe indicar la naturaleza de un problema a un profesional médico, quizás usando gestos y lenguaje verbal (Consejo de Europa, 2018: 89)

Si consideramos que el aprendizaje de una lengua, ya sea L1 o L2, no consiste en una mera memorización de listas de palabra ni en la capacidad infinita de construir frases, debemos diseñar un proceso didáctico que permita a nuestros estudiantes transferir los conocimientos teóricos a situaciones concretas donde haya que ponerlos en práctica.

\footnotetext{
${ }^{4}$ El énfasis es nuestro.
} 
En el aprendizaje descubrimiento, por ejemplo, no se imparte el contenido de forma directa, sino que está fundamentado en la experiencia, en la acción de interactuar con el entorno y los conocimientos. De esta manera, los alumnos pueden asimilar nueva información con aspectos relevantes y preexistentes en su estructura cognoscitiva, lo que permite ir ampliando las ideas previas. Por eso resulta imprescindible para el docente conocer cuáles son los «anclajes» sobre los que nuestros alumnos van a establecer los nuevos conceptos.

Esta es la base de la teoría del aprendizaje significativo de Ausubel (1976), que plantea que para que haya adquisición significativa de conocimientos, se requiere de dos condiciones: a) que el material sea potencialmente significativo, esto es, que permita relacionar la nueva información de manera sustancial y no arbitraria con los conocimientos previos de su estructura cognoscitiva del ser humano; y b) que el alumno manifieste una actitud, una motivación y disposición a aprender de esta manera y no a través de tareas repetitivas mecánicas, por ejemplo.

En este sentido, un laboratorio de idiomas como el que planteamos resulta un proyecto útil, ya que permite recrear situaciones cotidianas empleando objetos y materiales de la vida real. Así, los nuevos conceptos trabajados en las actividades realizadas estarán conectados con la experiencia previa de nuestros alumnos en su lengua materna, por lo que será más fácil que los interioricen de forma relevante. Cuando el alumno siente que los contenidos de clase tienen una aplicación en su vida real, puede desarrollar esa motivación o disposición positiva a seguir aprendiendo.

Además, la metodología que deviene este proyecto presenta un enfoque cooperativo (Landone, 2004, Cassany, 2009). En la mayoría de las actividades (véase el apartado 5.3), cada miembro del equipo asumirá un rol concreto: si hay una interacción en el escenario de «La oficina de viajes», habrá mínimo una persona perteneciente a la oficina y un cliente. El objetivo es diseñar una situación comunicativa problemática que haya de resolverse, crear el diálogo y representarlo. Puede que a lo largo del diseño de la conversación o incluso en la representación surjan problemas o inseguridades (véase apartado 6), pero la tarea común que existe por delante fomenta que haya una cohesión entre los miembros y que se trabaje conjuntamente para conseguir el objetivo. Además, ante el reparto equitativo, el alumno toma las riendas de su propio aprendizaje y comienza a asumir una responsabilidad hacia sí mismo y hacia sus compañeros para garantizar que la tarea sea exitosa.

\section{Experiencias en Europa}

Para disminuir el déficit de interacciones orales significativas y contextualizadas, este proyecto del Pueblo de los idiomas se está implementando actualmente como una posible solución en muchos centros educativos de Alemania y los Países Bajos ${ }^{5}$. No obstante, tras la consulta de los materiales disponibles en las direcciones web, hemos observado que ninguno de estos centros dispone de un espacio fijo en el que se ubique el Sprachdorf, sino que utilizan las aulas convenciones o los salones de actos o salas multiusos de grandes dimensiones para realizar las actividades. Esto es una solución parcial, la cual comentaremos más de forma más detallada en el apartado 6.1.

\footnotetext{
${ }^{5}$ Véase el anexo, en el que hemos presentado un cuadro-resumen con la relación de centros alemanes y neerlandeses que están realizando también este tipo de proyectos.
} 


\subsection{EI Sprachdorf del Dossenberger Gymnasium: espacio fijo integrado}

La iniciativa que aquí presentamos surge en el instituto Dossenberger Gymnasium de Günzburg (Baviera, Alemania) ${ }^{6}$ y los aspectos que la diferencian frente a otros proyectos similares son dos: por una parte, el espacio en el que se ubica el Pueblo de los idiomas es fijo y se corresponde con un aula normal del centro, la cual ha sido destinada para este fin y está concebida como un «laboratorio» más del centro. Por otra parte, el diseño y la creación de gran parte de los «escenarios» y decorados, como vemos en la imagen 1, son estéticamente muy atractivos y cuentan con múltiples detalles, lo que provoca un efecto de verosimilitud y realidad muy potente, pero al mismo tiempo, mantiene una atmósfera de teatralidad.

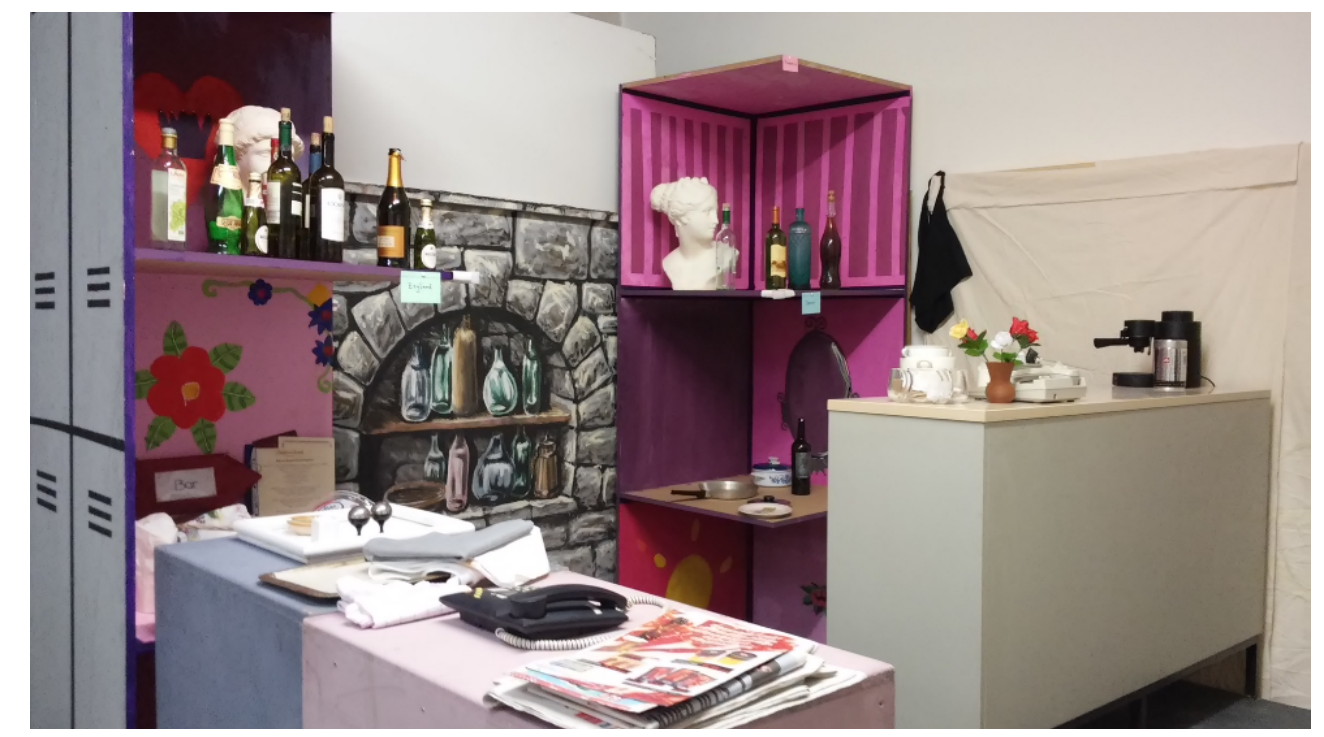

Imagen 1: Fotografia correspondiente al escenario de «El bar-restaurante» en el Dossenberger Gymnasium.

El proyecto surgió en forma de una colaboración interdepartamental: desde el departamento de Artes Plásticas se ofertó como actividad extraescolar la realización de diferentes escenarios y materiales para representar una obra de teatro. A su vez, como actividad dramatúrgica se ofreció crear el guion de una obra y su interpretación. Finalmente, el resultado de ambos seminarios se entrelazó, y los decorados fueron utilizados en la representación de la pieza. Sin embargo, el trabajo no terminó en ese punto, sino que los profesores implicados decidieron darle utilidad a todo el material reunido y creado: pensaron que, si los alumnos entraban en contacto con un lugar «real», con elementos reales y cotidianos, podrían entablar conversaciones espontáneas en la lengua que estaban aprendiendo y que les sería más sencillo, por ejemplo, despojarse del miedo inicial o la ansiedad idiomática que algunos sufrían normalmente en el aula (Brosig 2019).

Tomando estas ideas como punto de partida, el grupo de profesores acordó con el equipo directivo establecer en un aula concreta como espacio fijo para las asignaturas de idiomas, que, en el caso del centro, eran Inglés, Español, Francés e Italiano. Los docentes se coordinaron entre ellos, el personal del centro, alumnos y familias para recopilar todos

\footnotetext{
${ }^{6}$ Fuimos testigos del funcionamiento de esta propuesta de trabajo en el marco de nuestra estancia en Alemania como profesores ayudantes en institutos de secundaria gracias a la beca del Ministerio de Educación para Auxiliares de Conversación durante la convocatoria de 2015/2016.
} 
aquellos objetos a los que podría darse un segundo uso (Brosig 2019: 7): ropa y complementos, alimentos de plástico, platos, vasos, botellas vacías, teléfonos y ordenadores viejos, mapas de viaje, pósteres, folletos de viaje o entradas a monumentos turísticos, entre otros.

Así, crearon los siguientes «escenarios»:

1) Una tienda de ropa;

2) Un bar-restaurante;

3) Una oficina de viajes;

4) Una oficina de turismo/taquilla de edificios turísticos;

5) Un puesto de un mercado semanal;

6) Una oficina de atención en un aeropuerto;

7) Un pequeño centro médico.

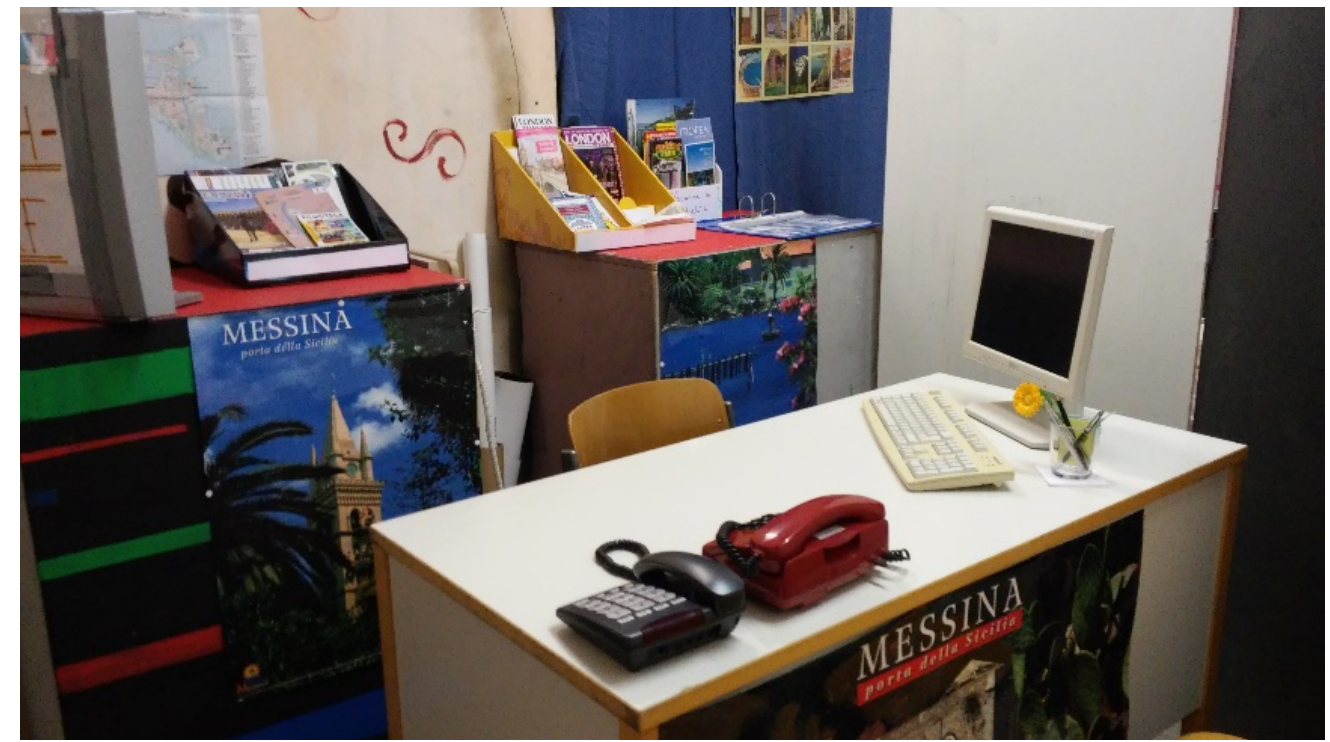

Imagen 2: Fotografia correspondienta al escenario de «La oficina de viajes» del Dossenberger Gymansium.

Como consecuencia, este proyecto consiguió que una gran parte de la comunidad educativa de ese centro llevara a cabo una actuación de mejora educativa de forma cohesionada. Además, se creó una red de trabajo sana y productiva que dio como fruto un mejor ambiente de trabajo en el centro.

Llegados a este punto, vamos a explicar el funcionamiento de uno de los «escenarios» más productivos (Lleixà, 2001, Bigas y Correig, 2001, Gobert, 2018) por la facilidad de recreación y de contextualización de las interacciones orales que puede dar lugar. Este es «El restaurante», el cual está perfectamente relacionado con el tema de la alimentación y los servicios, que es transversal en todos los niveles de enseñanza. 

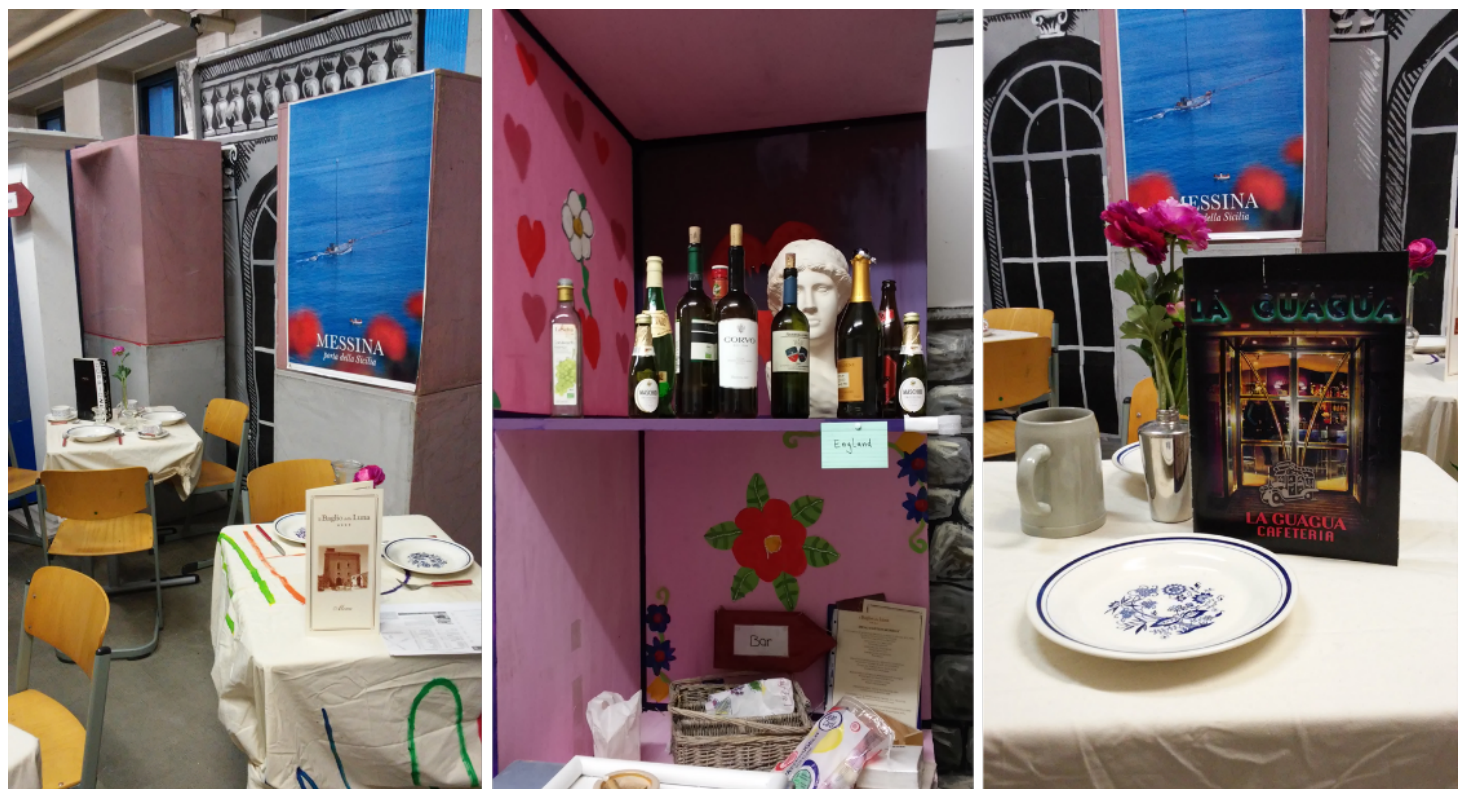

Imagen 3: Detalles de comedor, almacén y mesa correspondientes al escenario de «El barrestaurante» del Dossenberger Gymnasium.

Se han de emplear varias sesiones en las que se combine el aprendizaje de contenidos culturales (las diferentes comidas y horarios), léxicos (alimentos, bebidas, objetos), gramaticales (oraciones interrogativas, presente de indicativo) y pragmáticos (tratamiento de usted, uso de fórmulas de cortesía). En este contexto situacional interactúan varios participantes (clientes, camareros y personal de cocina) con propósitos comunicativos muy diversos como los siguientes: saludar, preguntar por el menú del día, explicar la carta de platos y bebidas, convencer del plato estrella de la casa, explicar los ingredientes y los pasos para cocinar una receta, exponer con educación una necesidad o una queja, disculparse, recibir un cumplido, pedir la cuenta, agradecer la propina, recomendar algún lugar para visitar o despedirse.

Pues bien, en lugar de servirse únicamente del libro de texto, de las TIC (Tecnologías de la Información y la Comunicación), y de otros recursos audiovisuales, cuya utilidad es innegable, se pretende que la clase se traslade a este nuevo espacio para que los alumnos practiquen algunas de estas situaciones comunicativas en un ambiente mucho más real y contextualizado.

En conclusión, este recurso metodológico se utiliza con el propósito de acelerar el proceso de adquisición de la competencia comunicativa, ya que permite potenciar la fluidez oral, mejorar la pronunciación, o entrenar las habilidades pragmáticas; dado que se dispone de más tiempo para practicar un mayor número de conversaciones que pertenecen a situaciones cotidianas de la vida real, los estudiantes pueden sentirse más motivados (Brosig 2019: 11), ya que podrían enfrentarse a ocasiones similares en el futuro, y, por ende, el esfuerzo de aprender cómo solucionarlas sí puede merecerles la pena.

\section{Preparación}

Para poder desarrollar un Pueblo de los idiomas, hemos de tener en cuenta varios aspectos: el primer punto es el espacio del que dispondremos en el centro. Es 
conveniente que cumpla unas condiciones mínimas de espacio, ventilación, iluminación y seguridad y su uso debería ser exclusivo del laboratorio lingüístico.

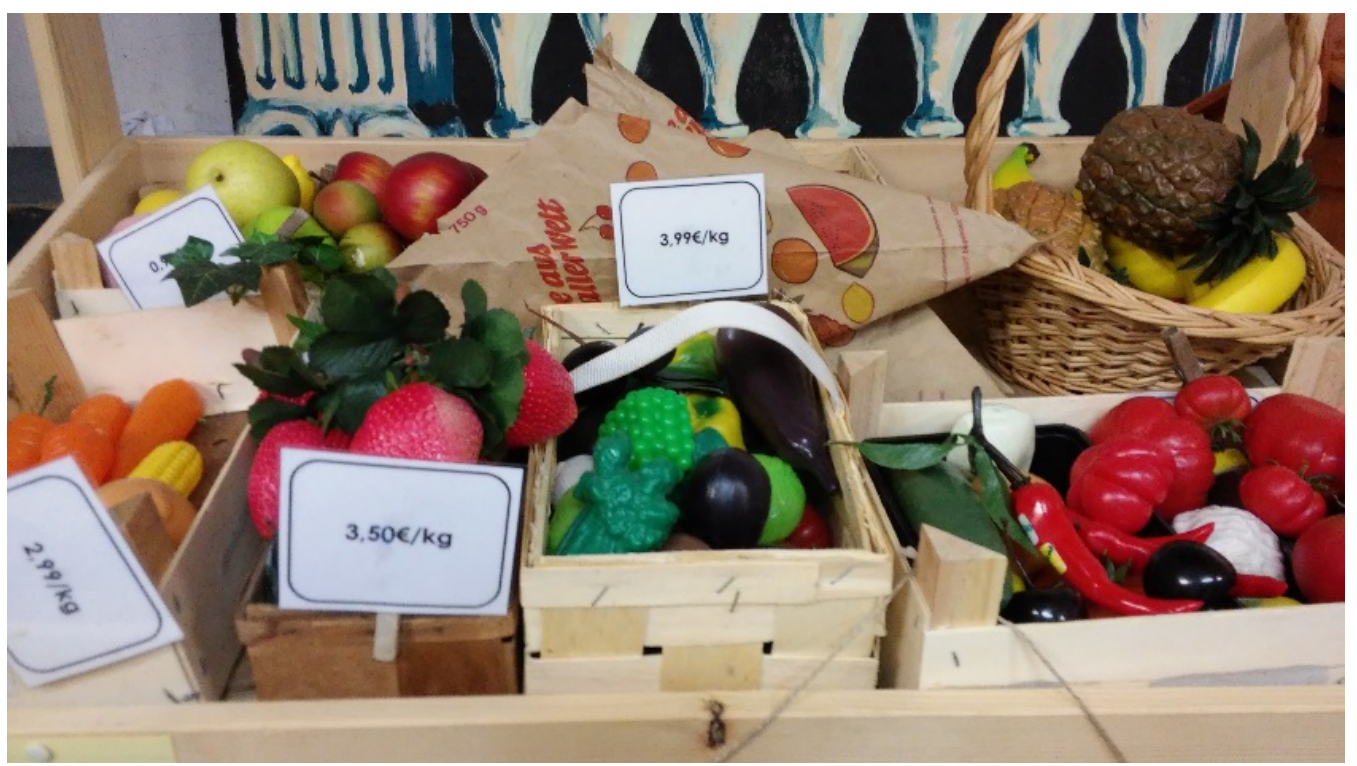

Imagen 4: Fotografia correspondiente al escenario de «El mercado» del Dossenberger Gymnasium.

El segundo punto son las estaciones o escenarios de interacción que se construyen; en el apartado 2.1 veíamos las propuestas de Brosig (2019), pero como apunta Bassedas et al. (2000: 177), se pueden ofrecer tantas alternativas como objetivos pedagógicos planteen los profesores y alumnos. Una vez elegidos los escenarios que quieran realizarse, se procederá a su diseño y construcción, cuyo grado de complejidad dependerá de las posibilidades técnicas y humanas de que dispongan los equipos docentes encargados. E1 Sprachdorf del Dossenberger Gymnasium contaba con decorados hechos en madera y con muchos detalles, ya que habían sido realizados por profesores de Artes y Dibujo.
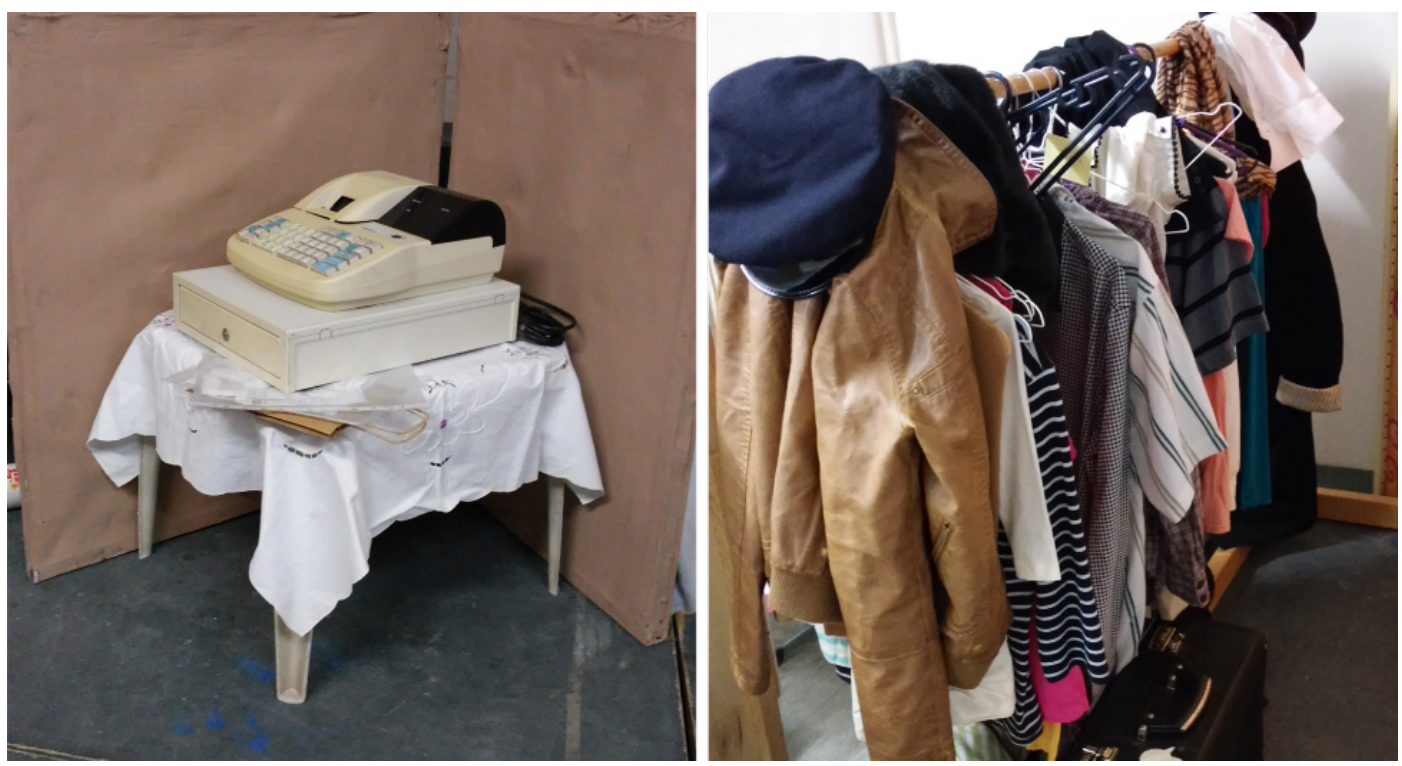

Imagen 5: Detalles de caja registradora y percha correspondientes al escenario de «La tienda de ropa» del Dossenberger Gymnasium. 
No obstante, si no contamos con estos perfiles en nuestro equipo, bastará con que los escenarios sean verosímiles y pueda trabajarse en ellos. Posteriormente, se procederá a organizar la recopilación de objetos por parte de profesores, alumnos y familias. Los criterios de selección deberán ser acordes a los objetivos didácticos que pretendan conseguirse; se priorizarán los objetos por su estado mínimo de conservación, con el fín de que puedan ser utilizados en el aula sin ningún peligro para los alumnos. Los objetos como botellas o envoltorios deberán haber sido limpiados previamente.

El tercer punto es fundamental y comprende las normas y las herramientas necesarias para garantizar el correcto funcionamiento del espacio. Es obligatorio contar con un armario para guardar todas las tarjetas de vocabulario, gramática y el resto de las fichas de trabajo. Hay que insistir en la responsabilidad de los alumnos en cuanto al orden y al buen uso de las instalaciones, idea que también está relacionada con la normalización e integración de este recurso en el funcionamiento ordinario del centro educativo. Por otra parte, como opción complementaria, se ha de reservar un espacio de trabajo con material de consulta, como ordenadores, manuales o diccionarios. Esto ayuda a resolver dudas concretas por los alumnos y permite una mayor autonomía en el proceso formativo. A su vez, facilitaría el trabajo por turnos de los equipos de trabajo, ya que mientras unos realizan las interacciones orales, el resto se ocupa de otro tipo de ejercicios.

\section{Metodología}

Desde el principio hemos afirmado que concebimos el laboratorio de idiomas como un recurso metodológico. Si bien puede servirnos como actividad final de una unidad temática, creemos que puede aprovecharse en mayor medida si se contempla como secuencia metodológica, puesto que permite integrar más de un contenido del currículum (Spurr, 1942).

En primer lugar, hemos de tener en cuenta que el proceso de aprendizaje está secuenciado en diferentes fases de trabajo, las cuales hoy en día se encuentran muy estratificadas en las diferentes programaciones anuales de cada asignatura. Por ello, como se ha apuntado en el apartado 2.1, se han de combinar contenidos léxicos, gramaticales, pragmáticos y culturales. Si, por ejemplo, nos encontramos en un curso de $3^{\circ}$ de la ESO o en una clase de nivel $\mathrm{B} 1$ y decidimos dar el tema de las compras, y más concretamente el de la ropa, podemos empezar con el léxico de las diferentes prendas y complementos, así como adjetivos para describir color, tamaño o precio. Más tarde, podemos trabajar variadas estructuras y su función comunicativa: presente de indicativo para las acciones o las descripciones, sobre todo de verbos irregulares como ser, estar, tener, o querer; estructuras interrogativas para preguntar por el precio, la talla o el color; o también podemos el condicional para expresar cortesía.

\subsection{Primera fase de actuación: tarjetas de memorización}

Una de las primeras sesiones que se pueden plantear en el laboratorio de idiomas in situ trataría sobre un primer acercamiento al contenido léxico. Podemos utilizar cartulinas con los nombres de las prendas y pedir a nuestros alumnos que vayan probándose la ropa e intentando unir palabras con realidades ${ }^{7}$.

\footnotetext{
${ }^{7}$ Por cuestiones de espacio, en este trabajo no se presenta de forma sistemática la estructura de una unidad didáctica que tenga por protagonista el empleo de este espacio. No obstante, en cuanto a esta primera
} 
Uno de los elementos claves que comprende esta primera fase de aprendizaje es el empleo de spickers o tarjetas de vocabulario. Brosig (2019) explica que una estrategia de memorización del vocabulario es escribir el nombre de todos los objetos que se hallan en el espacio. Esta es una tarea que puede realizar el profesor previamente, aunque en ocasiones puede utilizarse el tiempo de clase para trabajar el género y número de los diferentes sustantivos. Por ejemplo, en el caso de la ropa, crearíamos una tarjeta como la chaqueta, las chaquetas y la colocaríamos en algún bolsillo de este objeto. Así, cuando necesiten decir esta palabra y no la recuerden, podrán encontrarla fácilmente.

En función de las lenguas que se enseñen en nuestro centro, podemos optar por las tarjetas multilingüe; Brosig (2019: 10) pone el ejemplo de la tarjeta la cebolla, en la que aparece una fotografía de esta hortaliza y sus diferentes voces en inglés, francés, español e italiano: onion, l'oignon, la cebolla y la cipolla. Esta nueva estrategia actualizaría a la anterior y fomentaría una competencia interlingüística, ya que los estudiantes podrían ver las similitudes entre una misma familia lingüística, analizar los préstamos que unas lenguas reciben de otras y ampliar su vocabulario en otras asignaturas de idiomas.

Los contenidos grama-pragmáticos también están recogidos en otra serie de tarjetas. Si pensamos ahora en la estación o escenario del mercado, al realizar la función comunicativa de preguntar por el precio de un objeto, se nos vienen a la mente muchas opciones, unas que aprendemos en el nivel inicial (¿Cuánto cuesta? ¿Cuánto vale?) y otras que van incrementando la complejidad (¿Cuánto es? ¿Cuánto le debo en total? Estas manzanas están un poco pochas ¿qué tal si le doy...?) y otras alternativas. Como posible -y quizás temporal- solución al hecho de aunar diferentes ritmos de aprendizaje, Brosig (2019) establece tres niveles de dificultad: fácil (verde), medio (naranja) y difícil (rojo). Por tanto, en el puesto del mercado, cuando los alumnos vayan a practicar e interiorizar la función interrogativa en la L2, colocarán esta tarjeta para preguntar por el precio a la vista y buscarán, en función de la dificultad y el color asignado, la expresión que hayan trabajado o entiendan.

El proceso de aprendizaje de contenidos gramaticales sí que suele realizarse más frecuentemente en el aula convencional, por eso en ningún momento concebimos que el laboratorio de idiomas sea un sustituto permanente de esta: ambos espacios son y han de funcionar complementariamente.

\subsection{Segunda fase de actuación: práctica sin tarjetas}

Tras el proceso de memorización de los conceptos, se procede a una segunda fase de actuación, donde las actividades de interacción oral serán el foco central del aprendizaje; a su vez, otro objetivo secundario es que los estudiantes dejen de necesitar progresivamente estas «chuletas» para poder expresarse, ya que, después de muchos ejercicios de práctica, habrán memorizado los objetos y las funciones comunicativas que necesitan utilizar.

En esta segunda fase, como decimos, trabajaremos las habilidades pragmáticas y desarrollaremos los subcomponentes de las competencia comunicativa, como la fluidez, la pronunciación, o cuestiones más específicas de las normas de cada lengua y cultura: por ejemplo, sería interesante en la asignatura de Español enseñar a nuestros alumnos a que la interrupción y el solapamiento conversacional entre iguales es un signo de

actividad, puede plantearse por grupos, para que después presenten sus hallazgos y que, entre el profesor y el resto de los alumnos, vayan confirmando o corrigiendo las intuiciones. 
mantenimiento de la atención: cuando realizamos los llamados turnos de apoyo (Cestero, 2017), tales como sí, ajá, claro, ya te digo. Incluso es pertinente enseñar que cuando nos mostramos colaborativos con nuestro interlocutor pidiéndole más información o preguntándole por más detalles o mostrando acuerdo con lo que dice, le estamos diciendo implícitamente: te escucho. Por el contrario, si mientras alguien nos cuenta algo, no decimos nada, nuestro compañero de interacción puede pensar que este tema no nos interesa. Esta noción sociocultural es fácilmente trabajable en contextos bien delimitados en los que podemos crear situaciones cotidianas de habla, como amigos en una tienda de ropa una pareja en un mercado o una familia en el restaurante, entre otros.

\subsection{Actividades}

Las actividades que pueden realizarse son de diversos tipos: Brosig (2019) afirma que es preferible dejar experimentar a los estudiantes durante las primeras sesiones de Sprachdorf. Así, pueden adentrarse poco a poco en él, interactuar autónomamente con el entorno, como en una especie de juego libre. Esta idea es similar a la que se defiende desde la didáctica en Educación Infantil, pues el contacto con los materiales, la imaginación y las posibilidades de expresión individual y colectiva son los ingredientes para despertar su creatividad y motivación.

Otro tipo de dinámica es la interpretación de diálogos previamente trabajados en clase o incluso extraídos del libro o de otros recursos; con ellos pueden trabajarse fonemas y voces que presentan dificultades de pronunciación para nuestros alumnos.

Aun así, una de las tareas que más se utiliza con mejores resultados son las situaciones comunicativas diseñadas por los propios alumnos, las cuales se caracterizaban siempre de problemáticas: en ellas había elementos humorísticos y lúdicos que atraían tanto a los propios «actores» como al público oyente. En nuestra experiencia práctica pudimos comprobar cómo la imaginación de los niños y adolescentes se encuentra muy lejos de conocer sus limitaciones, por lo que fuimos testigos de historias divertidas y complejas. También se crean otras en las que no existen ningún elemento atípico; de hecho, desde una perspectiva estricta, podría considerarse que las situaciones que más se puedan parecer a la realidad son las únicas que pueden considerarse «significativas», si entendemos por ello que la práctica y el esfuerzo realizado cobra sentido por servir de preparación previa para la situación hipotética futura: dicho de otro modo, ante un problema, esto es, comunicarse en otra lengua y comunicar una intención, en este ejercicio aplicamos lo aprendido y vamos encontrando una serie de soluciones para poder expresarse.

Por último, también se contempla la grabación de pequeños cortometrajes para aprovechar las nuevas tecnologías y conseguir una mayor motivación en nuestros alumnos (Brosig 2019); este tipo de planteamiento conlleva una serie de pasos previos, como es la preparación del guion, la corrección, el reparto de tareas, la reflexión sobre los planos y las escenas o el diseño del vestuario. Más allá del gran esfuerzo que pueda suponer, este tipo de actividades, si se conciben desde una perspectiva "cooperativa», proporcionan una formación integrada de competencias, pues no solo se trabaja las habilidades comunicativas, sino que se aprende a trabajar en equipo, se aprende a aprender y a repartir roles y tareas, lo cual fomenta la autonomía y la responsabilidad en nuestro propio aprendizaje. 


\section{Experiencia práctica}

A continuación, expondremos las actividades que pusimos en práctica en el Sprachdorf del Dossenberger Gymnasium durante el curso 2015/2016. Se realizaron en el marco de un taller extraescolar voluntario denominado «Curso de conversación», que fue ofertado a todos los estudiantes de español, con una duración de cuarenta y cinco minutos semanalmente. Su objetivo era mejorar las destrezas orales, ampliar léxico y resolver dudas. Tras las primeras semanas de prueba, el grupo se consolidó en unas diez alumnas, principalmente de los cursos correspondientes a $3^{\circ}$ y $4^{\circ}$ de la ESO. Durante los siguientes siete meses, repasamos los contenidos que iban apareciendo en clase (partes del cuerpo, adjetivos de descripción, diferencias entre el pretérito imperfecto y el pretérito perfecto, jóvenes y aficiones, o Navidad); hacia el final del curso, trabajamos en el laboratorio de idiomas a partir de la siguiente secuenciación:

- En la primera sesión, visitamos el espacio y organizamos a las alumnas en pequeños grupos para que exploraran libremente los escenarios. Nuestro papel era acercarnos y observar qué tipo de interacción realizaban y qué contexto habían propuesto, así como corregir los errores que advertíamos. Al finalizar esa sesión, propusimos a los grupos que pensaran en pequeñas situaciones que quisieran representar en las próximas clases.

Como novedad frente a todos los tipos de actividades que podían realizarse (véase el apartado 5.3), introdujimos en la creación y representación de situaciones un elemento lúdico. Queríamos practicar los cambios entonativos que conllevan las expresiones de sentimientos como alegría, enfado, sorpresa o tristeza, por lo que creamos unas cartulinas con todos estos conceptos. Cuando el grupo estuviera representando la situación, una de las compañeras avisaría a una o a todas las participantes y les mostraría el sentimiento. Así, los enunciados que fueran a producirse con posterioridad tendrían que ser expresados de la manera propuesta por los compañeros; además del efecto humorístico que crearíamos, estaríamos fomentando el esfuerzo por realizar diversas entonaciones, aspecto que en ocasiones se echa en falta en el discurso de hablantes no nativos de español.

- En la segunda sesión, los grupos terminaron de perfilar las situaciones y roles y comenzamos el trabajo de reflexión gramatical sobre las estructuras que podrían necesitar. Resolvimos dudas de este tipo y también de léxico. Cuando lo tenían claro, comenzaba el trabajo de ensayo breve en el escenario.

- La tercera sesión tuvo dos partes: en la primera continuaron con los ensayos de la situación y en la segunda, hacia el final, la representaron delante del resto de estudiantes. Por último, y después de que los alumnos nos hubieran dado su consentimiento previo, estos pequeños intercambios fueron grabados personalmente con nuestra cámara.

- En la cuarta sesión volvimos al aula convencional y proyectamos los cortometrajes; esto nos sirvió para realizar un proceso de autoevaluación por parte de los alumnos y también de corrección de los principales errores. Por supuesto, para ellas fue muy divertido, pero también gratificante, el hecho de verse antes problemas como quedarse en blanco por desconocer una palabra o un tiempo verbal, y poder solucionarlo, 
gracias a la ayuda de las compañeras, quienes compartían el objetivo de enfrentarse a una situación comunicativa y de que esta fuera comprendida.

Por cuestiones de espacio, solo comentaremos los principales resultados de dos de las representaciones grabadas: la primera realizada en «El bar-restaurante» y la segunda, en «La tienda de ropa». En la última implementamos la variación lúdica de cambios entonativos que hemos propuesto. Hemos realizado la transcripción de las conversaciones mediante el sistema del grupo Val.Es.Co (Briz y Val.Es.Co 2014) para poder analizar en profundidad los fenómenos lingüísticos ${ }^{8}$.

En primer lugar, en ambas situaciones los equipos trabajaron de forma cooperativa: crearon las situaciones y se repartieron roles diferentes. Así, aunque hay alumnas que llevan el peso de la interacción por encima del resto, todas participan y hacen participar a las demás: cuando un miembro del equipo se pierde o no sabe continuar, recibe ayuda por parte de sus compañeras; asimismo, si alguien se equivoca, los compañeros colaboran y corrigen su error, por lo que este elemento posee una función didáctica muy importante en el aprendizaje.

En segundo lugar, en ambas situaciones se trabajan múltiples contenidos del currículum interconectados: vocabulario de los alimentos en el restaurante, y de la ropa y el color en la tienda; contenidos gramaticales como el presente de indicativo de verbos regulares e irregulares, algunos tiempos en pasado y el condicional, así como perífrasis verbales. En cuanto a las funciones comunicativas, se realizan saludos, preguntas, peticiones de confirmación, expresión de gustos y disculpas. Como contenidos pragmáticos, observamos también fenómenos de intensificación lingüísticos, como la repetición de estructuras, y paralingüísticos, como la elevación del tono en algunas secuencias.

En tercer lugar, y pese al número alto de vacilaciones y pausas en el discurso de la mayoría de las alumnas, observamos interacciones fluidas, en las que las intervenciones que suceden simultáneamente a otras; por ello, podemos decir que existe un desarrollo conversacional válido y que las intenciones comunicativas son reconocidas. Hay mayor fluidez conversacional que una interacción docente-alumno, y pese a que no existen apenas solapamientos e interrupciones, la rápida sucesión de los turnos de habla ya puede significar un pequeño triunfo en clase de E/LE, que contrasta con los diálogos irreales de los manuales.

En cuarto lugar, el contenido lúdico y humorístico estaba presente en ambas situaciones, especialmente en la segunda, donde la introducción de los cambios entonativos resultó muy divertida. Todas han sabido responder con gran acierto, tanto verbal como gestualmente, lo que abre la puerta a dedicar más tiempo en clase para tratar aspectos sociales y pragmáticos de la interacción, así como habilidades de comunicación no verbal, ya que ambos contenidos resultan fundamentales a la hora de conversar y de comunicar con éxito nuestras intenciones.

\subsection{Un laboratorio en la mochila}

En el caso de que no se disponga en el centro de un espacio fijo para el laboratorio, es posible implementar este proyecto de manera itinerante y temporal en el aula convencional de clase. Así es como hemos observado que actúan en algunos centros de

\footnotetext{
${ }^{8}$ En el anexo pueden consultarse las dos transcripciones. Véase Briz y Grupo Val.Es.Co., 2014 para resolver cualquier duda sobre los símbolos del sistema de transcripción.
} 
Alemania y Países Bajos (véase el apartado 2 y el anexo). En nuestro caso, nos gustaría explicar nuestra experiencia práctica. En el instituto Maria Ward Gymnasium de Günzburg no existe ningún Sprachdorf fijo, pero, aun así, quisimos ver de qué manera podía realizarse dicho proyecto en un grupo de $4^{\circ}$ de la ESO que había empezado en ese curso a estudiar español.

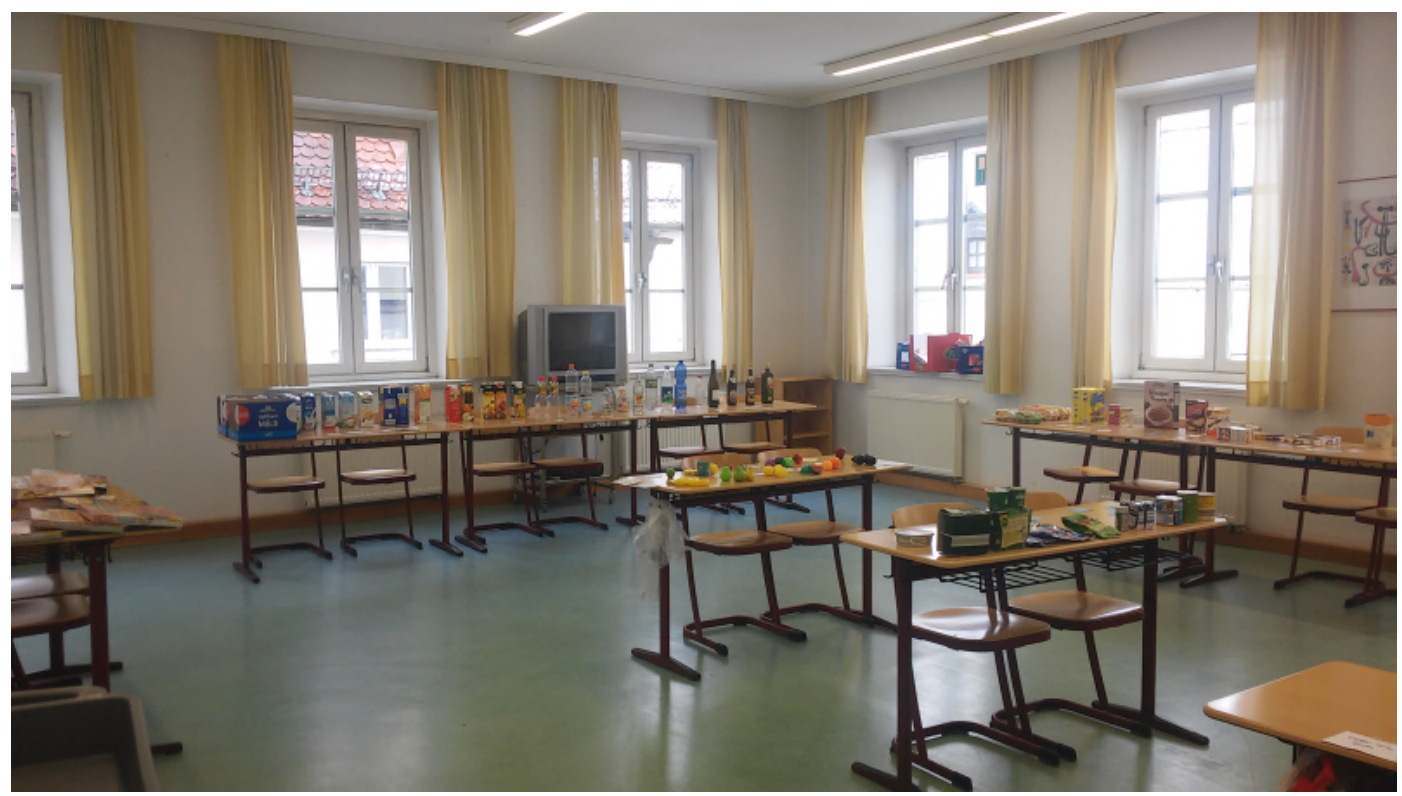

Imagen 6: Fotografia de un aula convencional transformada en el escenario de «El mercado» del Maria Ward Gymnasium.

Durante varios meses recopilamos botellas, cajas de huevos o envoltorios de comida; además, la profesora de español nos facilitó de su casa frutas de plástico y una caja registradora de juguete. Una vez recogido el material, creamos las tarjetas de vocabulario y las clasificamos según la sección del supermercado (frutas y verduras, bebidas, productos de desayuno, pizzas, y otros), que iba a coincidir con la estación o escenario. Además, en la pizarra escribimos las ofertas del día y los precios de los productos.
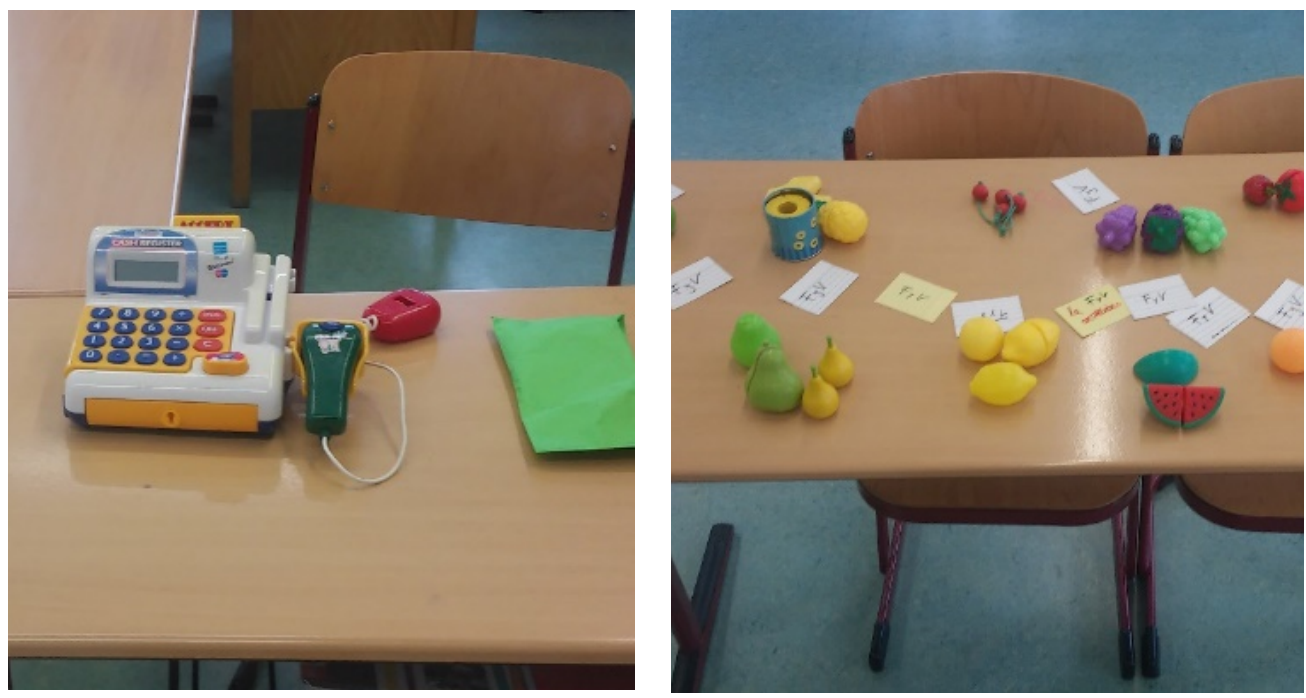

Imagen 7: Detalle de caja y frutas en el escenario «El supermercado» dentro de un aula convencional del Maria Ward Gymnasium. 
En la primera sesión se trabajaron los contenidos léxicos: se dividió a la clase en grupos de tres o cuatro alumnas y se les pidió que colocaran las tarjetas de vocabulario junto al objeto correspondiente. Después confirmamos las intuiciones y las alumnas anotaron las palabras en su cuaderno, al tiempo que repasábamos el género y el número de los sustantivos. Tras finalizar la sesión, recogimos el material y lo guardamos en un pequeño almacén cercano al aula.
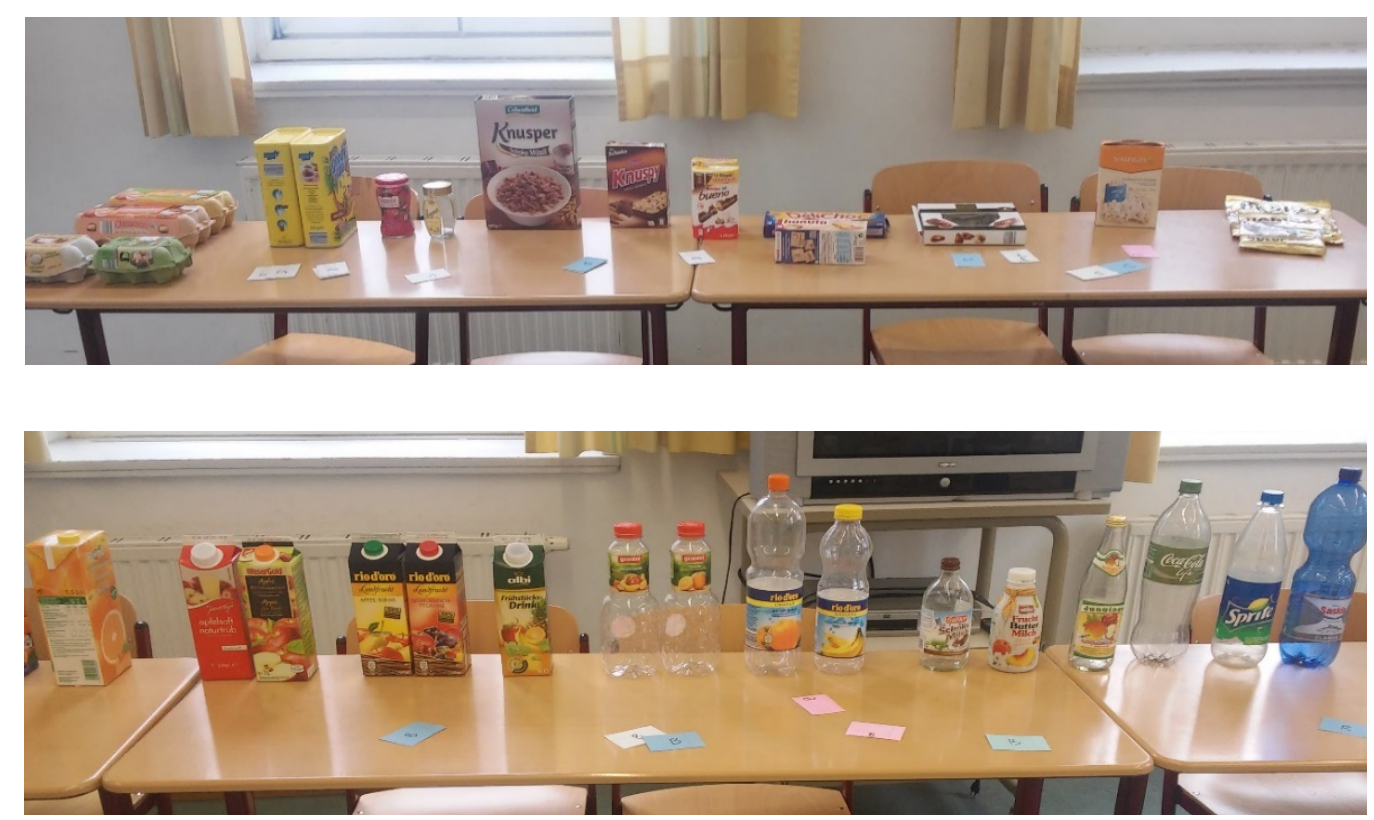

Imagen 8: Botellas y envoltorios en el escenario «El supermercado» dentro de un aula convencional del Maria Ward Gymnasium.

En la segunda sesión volvimos a colocar los objetos y trabajamos algunos contenidos gramaticales básicos como presentes de indicativo de los verbos tener, querer, ser y costar y estructuras interrogativas: ¿cuánto cuesta?, ¿qué quieres?, ¿tienes...?, entre otras. Nuestra función era la de pasar por los grupos y corregir los errores que surgían.

Pasadas unas sesiones, y dado que a las estudiantes les había parecida una muy buena idea, se volvió a realizar otra sesión similar a la segunda para volver a practicar nuevos contenidos léxicos (colores) y gramaticales (numerales). 


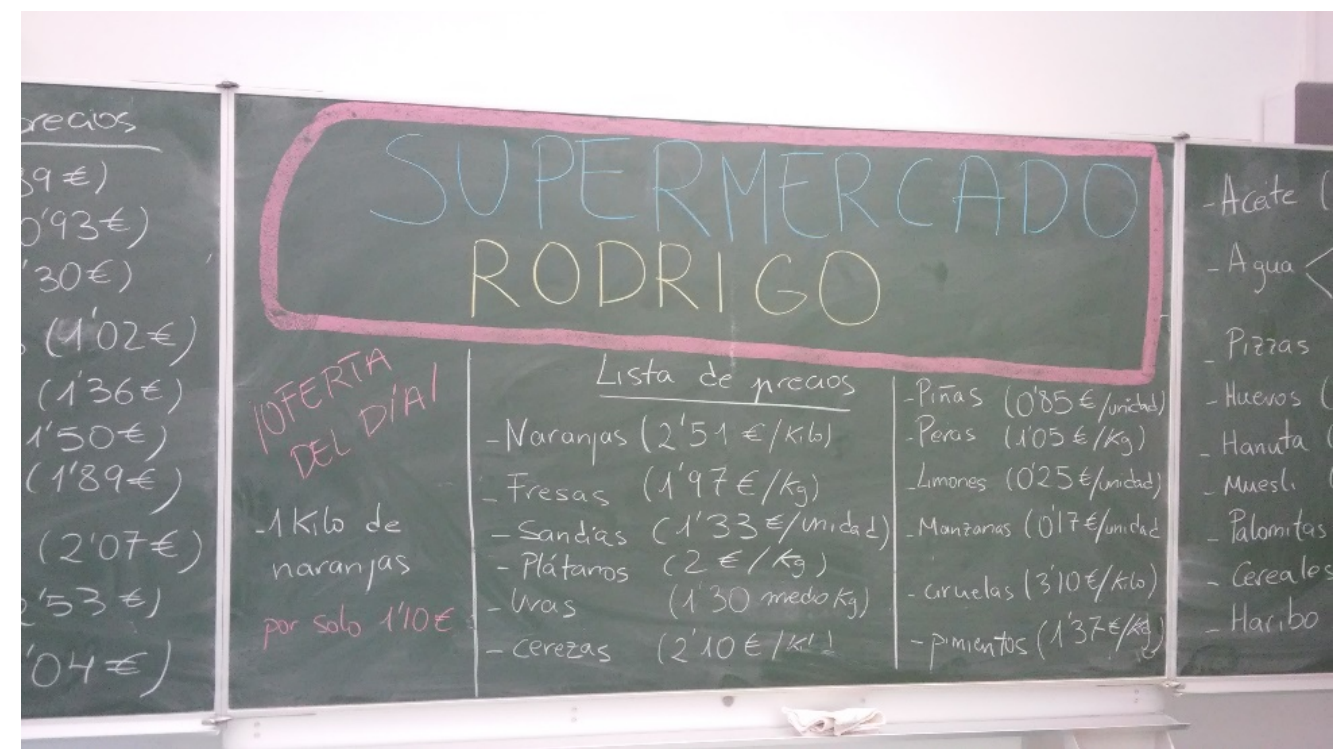

Imagen 9: Detalle de la pizarra con los precios en el escenario de «El supermercado» dentro de un aula convencional del Maria Ward Gymnasium.

En definitiva, pese a no contar con ningún espacio ni material previo y al gran esfuerzo que supuso, se pudo desarrollar un laboratorio de idiomas mínimo con éxito, dado que la valoración de las estudiantes y de la profesora fue muy positiva.

\section{Reflexiones finales}

Hemos presentado las características principales del proyecto del Sprachdorf o El Pueblo de los idiomas, sus raíces epistemológicas y la forma de preparación y de trabajo. Para cerrar nuestro trabajamos, pasaremos a comentar, a raíz de los resultados que hemos extraído en nuestras experiencias prácticas, los factores más relevantes que deben tenerse en cuenta.

- El recurso permite orientar el aprendizaje de la lengua desde un enfoque comunicativo hacia la acción (PCIC, 2006, MCER, 2002, 2018) y así puede solucionar la falta de interacciones orales en el aula. En este espacio, el profesor no es el interlocutor principal de los alumnos, sino que ellos, en equipos de trabajo, practican situaciones comunicativas nuevas y delimitadas, donde han de realizar tareas con éxito mediante el lenguaje.

- Desde que los estudiantes entran al aula, tocan e interactúan con un entorno verosímil, lleno de objetos, de localizaciones y escenarios, lo cual, como se destaca en la didáctica de otras etapas educativas, fomenta la curiosidad, creatividad y la experiencia. Si hay experiencia, se pueden asimilar nuevos conceptos y vincularlos de forma relativa y duradera con otras ideas previas que se tienen. Esto es un principio básico de la teoría del aprendizaje significativo de Ausubel (1976). En el Sprachdorf se dan los dos requisitos que Ausubel establece para que se produzca significatividad en el aprendizaje: materiales significativos, que conecten las ideas nuevas a los conocimientos previos de manera, y una actitud motivadora hacia aprender de esta forma significativa. Por tanto, el problema de la falta de actividades orales (Cordeiro, 2018) y del bajo nivel de competencia comunicativa puede solucionarse porque se propone un aprendizaje significativo de los contenidos: en 
estos escenarios los estudiantes de hoy serán los trabajadores, turistas o ciudadanos del mañana, quienes viajarán al extranjero y podrán expresarse en una lengua diferente, puesto que ya han practicado situaciones cotidianas como pedir en un restaurante, reclamar un error en la factura o reservar una habitación de hotel. De esta manera, se solucionan dos problemas frecuentes en las clases de lenguas: «no se habla de nada importante» porque los ejercicios que se plantean son irreales y ficticios (Brosig, 2019) y «no se hace nada».

- Además, otro factor que comprobamos es que el enfoque cooperativo (Landone, 2004, Cassany, 2009) que subyace en las tareas orales planteadas propicia la cohesión entre los estudiantes, disminuye factores personales como la timidez o la ansiedad idiomática y otorga responsabilidad y autonomía en el proceso de aprendizaje. Si alguien comete un error o no sabe continuar, es ayudado rápidamente por los compañeros, para que la interacción global y las intenciones comunicativas sean comprendidas tanto por interlocutores por el resto de los alumnos espectadores. El error, por tanto, es un elemento fundamental en el proceso didáctico. A su vez, los factores lúdicos que proporciona el juego dramático o de roles son innegablemente positivos. Además de la risa por la propia situación en la interacción, hemos comprobado que la introducción de innovaciones, como los cambios entonativos, devienen en momentos muy cómicos y ricos en cuanto al desarrollo de habilidades paralingüísticas y de comunicación no verbal.

- Por otro lado, la grabación pequeños cortometrajes, además de ser gratificante y divertido para los participantes, ha resultado fundamental como instrumento y guía del proceso didáctico y evaluador, ya que dicho material proporciona al profesor un perfecto indicador de las fortalezas y debilidades de sus estudiantes con el que podrá saber qué aspectos han sido asimilados y cuáles no, y sobre esta base, tomar medidas.

- La consecuencia de que el Aula de idiomas posibilite un aprendizaje de contenidos orientado a la acción, con significado dentro y fuera del aula, es que la motivación, la disposición del alumno con respecto a la asignatura aumente. En consonancia con los resultados de otros trabajos sobre realia en Educación Infantil y en otros niveles, hemos sido testigos de que «jugar con el lenguaje» mediante todos nuestros sentidos, en contextos reales con objetos auténticos, permite a los alumnos experimentar, ser creativos y al mismo tiempo, sentir atracción por su proceso de aprendizaje. En resumen, si hablan más y mejor, el nivel de competencia comunicativa podrá mejorarse. Y si aprenden algo significativo, lo aprenderán dos veces.

En cuanto a los factores que deben controlarse, tendríamos que:

- Un Pueblo de los idiomas necesita inversión, esfuerzo y tiempo. Aun así, Spurr (1942) precisa que no se trata de emplear mucho tiempo, sino de emplearlo bien, por lo que por encima del criterio de «autenticidad», primaría la «verosimilitud». Como decíamos al principio, esto otorga un efecto de teatralidad que propicia la creatividad y la imaginación de los alumnos dentro del marco del juego dramático (Bassedas et al., 2000).

- Algunos autores advierten del peligro de que estas clases se conviertan en un caos salvaje donde todos «jueguen», pero no aprendan ni practiquen realmente. Al principio, y sobre todo con grupos iniciales, puede parecernos que sucede esto. Recordemos que una de las actividades propuestas es el juego libre; aun así, es importante que marquemos claramente las normas de utilización de la sala, tanto en 
cuanto a ruido como a orden y limpieza tras su uso. Otra manera de solucionar esto es el trabajo en pequeños grupos por turno; de esta manera, un grupo puede comenzar practicando mientras que el otro trabaja, o en el aula convencional o en un espacio de trabajo con mesas y otros materiales en el propio Sprachdorf.

En conclusión, así como los laboratorios son importantes para las asignaturas de Química, Física o Biología, la Sala de Ordenadores para Informática, o el Gimnasio para Educación física, el Sprachdorf o el Pueblo de Idiomas se concibe como un verdadero laboratorio lingüístico, que puede resultar imprescindible para solucionar la falta de practicidad y de interacción oral en las asignaturas de lenguas, tanto en contextos de inmersión y centros bilingües de primaria y secundaria, como en centros de enseñanza universitaria o en otras academias de enseñanza no reglada.

\section{Bibliografía}

Ausubel, D. P. (1976). Psicología educativa. Un punto de vista cognoscitivo. México: Trillas.

Bassedas, E. Huguet, T. y Solé, I. (2000). Aprender y enseñar en educación infantil. Barcelona: Graó.

Bigas, M. y Correig, M. (eds.) (2001). Didáctica de la lengua en la educación infantil. Madrid: Síntesis Educación.

BREBNER, M. (1898). The method of teaching modern languages in Germany. London: Cambridge University Press Warehouse. Recuperado el 15/04/19, de: http://gateway.proquest.com/openurl?url_ver=Z39.88-2004\&res_dat=xri:c19indexus\&rft_dat=xri:c19index:NSTC:19C-17215

Briz GómEZ, A. y GRUPO VAL.Es.Co. (2014). «Las unidades del discurso oral. La propuesta Val.Es.Co. de segmentación de la conversación (coloquial)», Estudios de Lingüística del Español, 35, 13-73.

Brosig, E. (2019). «Buch zu und ab ins Sprachdorf! Schüler setzen kompetenzorientierte Lernaufgaben in authentischer Theaterkulisse um», Praxis Fremsprachunterricht Basis, vol. 2-2019, 7-11.

CASSANY, D. (2009): «La cooperación en ELE: De la teoría a la práctica», Tinkuy: Boletín de investigación y debate, 11, 7-29. ISSN-e 1913-0481. Recuperado el 26/04/19, de https://dialnet.unirioja.es/servlet/articulo?codigo $=3303819$

Celce-Murcia, M. Y HiLleS, S. (1988). Techniques and resources in teaching grammar. Oxford: Oxford University Press.

Cestero, A. M. (2017). «La enseñanza de la conversación». En A. M. Cestero e I. Penadés (eds.); Manual del profesor de ELE (pp. 1013-1049). Alcalá de Henares: Universidad de Alcalá, Servicio de Publicaciones.

CONSEJO DE EUROPA (2002). Marco común europeo de referencia para las lenguas: aprendizaje, enseñanza, evaluación. Ministerio de Educación, Cultura y Deporte, Instituto Cervantes, Anaya. Recuperado el 24/04/2019, de: http://cvc.cervantes.es/ensenanza/ biblioteca_ele/marco/ 
CONCIL OF EUROPE (2018): Common European Framework of references for languages: learning, teaching, assessment. Companion Volume with new descriptors. Strasbourg: Council of Europe. Recuperado el 26/04/19, de: https://rm.coe.int/cefr-companionvolume-with-new-descriptors-2018/1680787989

CORDEIRO, D. M. (2018): Las inteligencias múltiples como herramienta para mejorar las destrezas orales en el aula de español como lengua extranjera: una investigación acción (Tesis doctoral). Valencia: Universitat de València.

CRU, A. L. et al. (1929). "The use of "realia" in the teaching of french», The French Review: American Association of Teachers of French Stable, 2(4), 299-312. Recuperado el 16/04/19, de: http://www.jstor.org/stable/379623

GOBERT, M. (2018). «Flash cards, realia, and Objects». En J.I. Liontas (ed.); The TESOL Encyclopedia of English Language Teaching ( $1^{\mathrm{a}}$ ed.), Hoboken, NJ: Wiley-Blackwell: John Wiley \& Sons. doi:10.1002/9781118784235.eelt0188. Recuperado el 16/04/19, de: https://onlinelibrary.wiley.com/doi/pdf/10.1002/9781118784235.eelt0188

HeLD, H. K. (1938). «Bringing France and Germany to american schools», The Modern Language Journal, 22(5), 339-342. doi:10.2307/317931. Recuperado el 16/04/19, de: https://onlinelibrary.wiley.com/doi/pdf/10.1111/j.1540-4781.1938.tb02739.x

InSTITUTO CERVANTES (2006). Plan curricular. Niveles de referencia para el español. Madrid: Biblioteca Nueva.

LANDONE, E. (2004). «El aprendizaje cooperativo del ELE: Propuestas para integrar las funciones de la lengua y las destrezas colaborativas», RedELE: Revista Electrónica de Didáctica ELE, ISSN 1571-4667. Recuperado el 27/04/19, de: http://www.educacionyfp.gob.es/dam/jcr:c1854275-f46d-487f-98a4-

36eb4fb313d6/2004-redele-0-16landone-pdf.pdf.

LleIXÀ, T. (coord.) (2001). La educación infantil (0-6 años). Vol. II: Expresión y comunicación. Barcelona: Paidotribo.

Milone, A. (1937). «Realia as applied in the italian classroom», The Modern Language Journal, 22(5), 353-358. Recuperado el 16/04/2019, de: https://search.proquest.com/docview/1290695429

SPURR, F. S. (1942). «Realia in foreign language courses», The Modern Language Journal, 26(3), 174-176. doi:10.1111/j.1540-4781.1942.tb01351.x Recuperado el 16/04/2019, de: https://www.jstor.org/stable/317495 
Anexo

1. Presencia de El Pueblo de Idiomas en centros de Alemania y los Países Bajos

\begin{tabular}{|c|c|c|c|}
\hline \multicolumn{4}{|c|}{ Alemania } \\
\hline Centro & Ciudad & Lenguas & Direcciones web \\
\hline $\begin{array}{l}\text { Werner-Jaerger- } \\
\text { Gymnasium }\end{array}$ & Nettetal & español & $\begin{array}{l}\text { https://www.wjg- } \\
\text { nettetal.de/index.php?id=547 }\end{array}$ \\
\hline Lessing-Gymnasium & Lampertheim & francés & https://www.lessing-gym.de/ \\
\hline $\begin{array}{l}\text { Robert Bosch } \\
\text { Gesamtschule }\end{array}$ & Hildesheim & alemán & $\begin{array}{l}\text { https://robert-bosch- } \\
\text { gesamtschule.de/sprachdorf/ }\end{array}$ \\
\hline Berufskolleg Borken & Borken & $\begin{array}{l}\text { holandés/ } \\
\text { alemán }\end{array}$ & $\begin{array}{l}\text { https://www.berufskolleg- } \\
\text { borken.de/taaldorp-sprachdorf/ }\end{array}$ \\
\hline $\begin{array}{c}\text { Institut für } \\
\text { Niederländische } \\
\text { Philologie } \\
\text { (Westfälischen-Wilhelms } \\
\text { Universität Münster) } \\
\end{array}$ & Münster & holandés & https://www.uni-muenster.de/INP/ \\
\hline $\begin{array}{c}\text { Maria Sibylla Merian- } \\
\text { Gesamtschule } \\
- \\
\text { Intercambio académico } \\
\text { con Erasmus University } \\
\text { Collegue Rotterdam }\end{array}$ & $\begin{array}{l}\text { Wattenscheid } \\
\text { (Bochum) } \\
\text { y } \\
\text { Rotterdam }\end{array}$ & $\begin{array}{l}\text { holandés/ } \\
\text { alemán }\end{array}$ & $\begin{array}{l}\text { http://www.msm.bobi.net/sprach } \\
\text { dorf.htm } \\
\text { http://wp.msm-ge.de/ } \\
\text { https://www.eur.nl/en/euc/ }\end{array}$ \\
\hline \multicolumn{4}{|c|}{ Países Bajos } \\
\hline $\begin{array}{l}\text { Oscar Romero Tabor } \\
\text { Collegue } \\
-\end{array}$ & Hoorn & español & $\begin{array}{l}\text { https://oscarromerotalen.nl/spaans/o } \\
\text { efeningen/ } \\
\text { Taaldorp-Flash/PuebloEspanol.htm } \\
\text { https://oscarromerotalen.n1/Duits/O } \\
\text { efeningen/ } \\
\text { Taaldorp-Flash/Sprachdorf.htm }\end{array}$ \\
\hline GSR Rotterdam & Rotterdam & alemán & https://gsr.nl/ \\
\hline $\begin{array}{c}\text { Willem Lodewijk } \\
\text { Gymnasium } \\
- \\
\text { Intercambio académico } \\
\text { con Zweite Piramatiko } \\
\text { Gymnasium en Grecia }\end{array}$ & Groningen & alemán & $\begin{array}{l}\text { https://www.wlg.nl/ } \\
\text { http://spreekprojecten.smartboarddu } \\
\text { its.nl/? } \\
\text { Sprachdorf }\end{array}$ \\
\hline
\end{tabular}




\section{Conversación en el restaurante}

Participantes: Tres alumnas: dos de la clase 9 ( $3^{\circ}$ de la eso, segundo año de español) y una de la clase 10 ( $4^{\circ}$ de la eso, tres años de español)

Acotación: A es camarera; B y C son clientas. A y B está sentadas en una mesa. C está levantada, delante de ellas. La mesa está cubierta con un mantel y sobre ella hay platos, vasos, cubiertos, un florero con una flor y un menú.

A: ¡buenos días!

B: [¡hola!¡buenos días]

$\mathrm{C}$ : [¡buenos días!]

A: ee ¿qué vas $\uparrow /$ aa / beber?

$\mathrm{B}:$ eem $\rightarrow$ queremoss $/{ }^{9}$ dos aguass minerales / por favor

C: sí

A: ¿yy / quieres / algo / para comer?

C: ¡sí! / eem los patataas $\uparrow / /$ emm los patatas ${ }^{10} \rightarrow($ RISAS $)$ con / ajo // ((¿wie?) $)^{11}$

B: ¡sí! una patata con ajoo $\uparrow-$ apro- $^{12}$ peroo ee / ES MUY IMPORTANTEE $\uparrow$ / quee / la patataa no es con mayonesa

A: okey

B: ¿entiendes?

A: sí

B: yy / yo quieroo / unaa // UN PESCADO

A: okey

B: ${ }^{\circ}(\text { por favor })^{\circ}$

A: un momento por favor (2', ) esto es / tu agua ${ }^{13} \uparrow$

B: igracias! §

C: $\quad$ \& igracias!

A: [yy]

B: [chin chin] (RUIDO) ${ }^{14}$

C: chin (2'')

A: estoo / es / las patatas yy- $\S$

C:

$\S$ igraciaas! §

A:

B: $((()))^{17}$ (RUIDO)

C: $(\text { TOSES })^{18}$

B: (RUIDO) ${ }^{19}$ ¿QUÉ EES? / ¿POR QUÉ ESTÁ MAYONESA EN ESO? §

C:

\footnotetext{
${ }^{9} \mathrm{~B}$ mira a $\mathrm{C}$ como esperando una respuesta

${ }^{10} \mathrm{~B}$ señala la foto del menú con un golpe, lo que provoca la risa de $\mathrm{C}$

${ }^{11} \mathrm{C}$ no sabe bien qué significa lo que pone en el menú y dice ¿wie?, que significa ¿cómo?

${ }^{12} \mathrm{~B}$ quiere decir apropos, que en alemán significa por cierto o a propósito.

${ }^{13}$ A hace como que le trae la bebida

${ }^{14}$ Ruido del brindis de las copas

${ }^{15}$ A hace como que le trae la comida

${ }^{16}$ B y C están comiendo los platos que les ha traído A.

${ }^{17} \mathrm{~B}$ le dice algo a $\mathrm{C}$ en alemán para que empiece a hablar.

${ }^{18} \mathrm{C}$ hace como si atragantara

${ }^{19} \mathrm{~B}$ coloca el plato con violencia sobre la mesa

${ }^{20} \mathrm{C}$ hace como si atragantara
} 
$\mathrm{B}$ :

¿POR QUÉ?

A: ¡porquee es la comida!

B: // di ${ }^{21}$ - di- (RISAS) $/ /$ ¿diji-? ${ }^{\circ}(¿ \text { dijimos? })^{\circ} \S$

$\mathrm{C}$ : $\S^{\mathrm{o}}\left(\right.$ dijimos $^{\mathbf{o}} \S$

$\mathrm{B}$ : $\S$ DIJIMOS que ES IMPORTANTE (RUIDO) ${ }^{22}$ que no está alguna mayonesa en ese $\S$ C: $\S(\text { TOSES })^{23}$

A: ¡lo siento mucho! ee voy a hablar con el jefe / [noo]

$\mathrm{B}$ :

SIENTO PERO $\uparrow$ / TENEMOS QUE IR AL HOSPITAL ${ }^{24} / /$ adiós
A: (RISAS)
C: adiós
B: (RISAS

\section{Conversación en la tienda de ropa}

Participantes: Cuatro alumnas de la clase 9 ( $3^{\circ}$ de la eso, segundo año de español) Acotación: A y B: son clientas; C y D: son dependientas; E y F son compañeras que hacen de público y proponen entonaciones. $\mathrm{G}$ es el profesor; hay un perchero con muchas prendas (chaquetas, pantalones, faldas, camisetas, botas, colgantes, gafas de sol, etc.) Hay un probador y una especia de estantería. C y D son dependientes y están esperando. A y B entran cogidas de la mano para comprar sendos trajes de boda.
A: $(\text { RUIDO })^{25}$
B: (RISAS) (5')
A: ¡hoola!
C: [holaa]
D: [holaa]
C: ¿((cómo)) podemos ayudar? //
$\mathrm{B}$ : ee quería ((a vender) $)^{26}$ un vestido BLANCO / para mii boda /
A: ¡síí! ¡queremos casarnos! ${ }^{27}$
D: ¿qué talla ${ }^{28}$ necesitas?
B: (2"') ee la tajaa trees yy cuatro
A: /// ¡yy yo necesito un traje! mhm ¡NEGRO! ${ }^{29}$ es- pero $\uparrow /[$ ee - ee] es precioso por
G:

\footnotetext{
${ }^{21}$ A realiza una pronunciación dental sorda / $\mathrm{t} /$ del fonema consonántico dental sonoro / $\mathrm{d} /$.

${ }^{22}$ Al tiempo que habla deja con violencia un vaso en la mesa.

${ }^{23} \mathrm{~B}$ hace como si se atragantara

${ }^{24}$ A no pronuncia la $h$ muda

${ }^{25}$ A silba una canción

${ }^{26}$ No sabemos bien qué dice B. Parece que es aprender, pero no tiene mucho sentido.

${ }^{27}$ A acerca su cabeza a B y sonríe en un gesto de complicidad dirigido a C y D

${ }^{28} \mathrm{D}$ pronuncia taja en lugar de talla

${ }^{29}$ A pronuncia la secuencia - $g r$ - con dificultad

${ }^{30} \mathrm{El}$ profesor hace un chasquido con los dedos para que A mire hacia él y vea el cambio de entonación que le propone
} 
A: favor (4’) ¿quién? ${ }^{31}$

E: (( ))

A: aber wer? ${ }^{32}$

Desconocido: $((()))^{33}$

E: alle $^{34}$

F: alle

G: ¡TODAS! ${ }^{35}$

B: (4') mm

$\mathrm{D}:$ [¿qué-?]

A: [¿qué ess-?] $\S$

C: $\quad \S$ ¿qué piensas sobre esto? $\downarrow^{36}$

A: // ¡oh!

B: $\mathrm{mm}$

A: ¿qué piensas? ${ }^{\circ}(\mathrm{du}((())))^{037}$

G: (RUIDO) $)^{38}$

$\mathrm{B}:$ no $\rightarrow$ ¡me gusta mucho! ${ }^{39}$

A: [¿muuchoo?]

$\mathrm{B}:[\mathrm{eem} \rightarrow]$ eel / eel // ${ }^{\circ}$ (was ist das? $)^{040}\left(2^{\prime \prime}\right)$

A: ${ }^{o}(\text { ¡negro! })^{\circ}$

B: ¡eel- el negro! [es muy bien]

$\mathrm{G}$ :

A: $[\text { es ffeeo } \rightarrow]^{42}$

$[(\mathrm{RUIDO})]^{41}$

G: [(RUIDO) $]^{43}$

A: ¡ES FEEO! ${ }^{44}$

B: [(RISAS)]

C: [(RISAS)]

D: [(RISAS)]

E: [(RISAS)]

F: [(RISAS)]

A: (2'’) ¡no me gusta! /// ¡un otro! por favor

B: // ¡mme GUSTA MUCHO!

A: ija! ${ }^{45}$

${ }^{31}$ A se dirige a las compañeras porque no entiende quién tiene que cambiar la entonación

${ }^{32}$ Dice ¿pero quién? en alemán, en referencia a quién tiene que cambiar la entonación

${ }^{33}$ Una compañera desconocida le indica en alemán que tiene que ser ella la que cambie el tono.

${ }^{34}$ Dice todas en alemán

${ }^{35} \mathrm{El}$ profesor aclara la situación y dice que todas deben cambiar la entonación propuesta por las compañeras.

${ }^{36}$ De fondo y a lo lejos suena el timbre que indica el final de la clase

${ }^{37}$ Dice tú y algo más en alemán, con la intención de que sea B la que realiza la entonación que le han propuesto antes

${ }^{38}$ El profesor hace un chasquido para que atiendan a otra petición de entonación

${ }^{39} \mathrm{~B}$ por fin realiza el enunciado con una entonación ALEGRE como le habían propuesto

${ }^{40}$ Dice ¿qué es esto? en alemán.

${ }^{41}$ El profesor vuelve a hacer varios chasquidos para que atiendan a la entonación propuesta

${ }^{42}$ A habla y al mismo tiempo se gira para

${ }^{43}$ El profesor vuelve a hacer varios chasquidos para que atiendan a la entonación propuesta

${ }^{44}$ A por fin ve la entonación de ENFADADA que le habían propuesto

${ }^{45}$ No sabemos si A dice ya en español o ja en alemán, que significa sí. 
D: yy $\rightarrow$

A: ¡sí! pero yo PAGO $\S$

D:

B:

$\S[$ ¿у este?]

E: [(RISAS)]

[¡ooh!]

G: [(RISAS)]

B: ¡ME GUSTA! ${ }^{46}$

A: ¡NOO! §

B: $\quad$ ¡ $\quad \mathrm{MUCHO} ! ¡ \mathrm{OOH}$ !

A: ¡no! ¡no puedo-! ¡NOO!

$\mathrm{C}: ~ ¿ \mathrm{y} /$ por qué no te gusta?

A: es // ¡ES FEO! ¡no!

G: (RUIDO) $)^{47}$

A: $/ /$ ¡ es feoo! ${ }^{48}$

B: [(RISAS)]

D: [(RISAS)]

C: [(RISAS)]

A: pero si- /// pero- me gustaría un traje $\uparrow$ / que / PRECIOSO $\uparrow / /$ por favor

$\mathrm{C}$ : // yy- ¿qué / piensa eso- ((por eso)) para [ti?]

$\mathrm{B}$ :

A:

B: ¡me gusta mucho también!

$[i \mathrm{~mm} !] \S$

A: ¡es feo también! §

$\mathrm{B}$ :

$\S$ ¡con flores!

G: (RUIDO) $)^{49}$

A: (3') das muss du $((()))^{50}$

B: ¡ah! ¡ME GUSTA MUCHO! ¡OH! ${ }^{51}$

A: ¡no! ¡no es un vestido!

C: si $^{52}$

A: y / ¡no es blanco!

$\mathrm{B}: / /$ ¡sí! ¡ es un vestido muy $\rightarrow$ / bueno! $\S$

A:

$\S$ ¡queremos casarnos! (2'’) ¡no queremos / ir /

a la PLAYA $\uparrow$ oo aa-! no sé

G: (RUIDO) $)^{53}$

$\mathrm{B}$ " $^{\circ}(\text { was heisst es? })^{054}$

Desconocido: ${ }^{\circ}(\text { ¡überrascht! })^{055}$

C: (RISAS)

${ }^{46} \mathrm{~B}$ sigue pronunciando la entonación de ALEGRE.

${ }^{47}$ El profesor hace un chasquido para avisar de una nueva propuesta de entonación.

${ }^{48}$ A realiza la entonación de TRISTE que le han propuesto.

${ }^{49} \mathrm{El}$ profesor hace un chasquido para avisar de una nueva propuesta de entonación

${ }^{50}$ A dice eso tienes que hacerlo tú y algo más en alemán y le indica a $\mathrm{B}$ que la entonación propuesta es para ella

${ }^{51} \mathrm{~B}$ realiza la entonación de MUY CONTENTO que le habían propuesto.

${ }^{52} \mathrm{C}$ habla con $\mathrm{D}$

${ }^{53} \mathrm{El}$ profesor hace un chasquido para avisar de una nueva propuesta de entonación

${ }^{54} \mathrm{~B}$ pregunta ¿qué significa eso? en alemán a A.

${ }^{55}$ Alguien dice isorprendido! en alemán. 
D: $[\text { ¿o aquí? }]^{56}$

Desconocido: $[((()))] \S$

$\mathrm{B}$ :

$\S$ ¡AAH! ¡oh! es esa- $\rightarrow\left(1,5^{\prime} ’\right)$ ¡es MUY bien! ¡me gusta muchí-

MUCHO!

A: ¡bah! ¡noo!

C: ¿y qué $((()))$ le gustaría?

A: $\left(1,5^{\prime \prime}\right)$ no sé $/ /$ pero $^{57} \rightarrow\left(2^{\prime \prime}\right){ }^{\circ}(((())))^{058} \S$

$\mathrm{B}$ :

G: (RUIDO) $)^{59}$

$\S$ ¡me gusta muy bien!

$\mathrm{B}$ : no quiero casar-

G: (RUIDO) $)^{60}$

$\mathrm{E}:((())))$

G: ${ }^{\circ}(\text { ¡die Verkäufer! })^{\mathbf{0} 61}$

C: $\left(2\right.$ '’) yy- ¡TRANQUILO! ${ }^{62}$

A: ¡horrible!

C: ¡ jesto es- eem- un- eem- es una- eem- (RISAS)

D: ${ }^{\circ}(\text { tienda })^{\circ}$

C: tienda $\uparrow$ de ropa! no es paraa-

D: ${ }^{\circ}(\text { vetreten })^{\text {o63 }}\left(6^{\prime \prime}\right)$

B: $((()))$

D: $((()))$

A: ${ }^{\circ}(\text { separ- })^{\circ}$

D: ¡no es para separarse! ${ }^{64}$

A: sí pero / ¡es horrible! ¡TÚ eres horrible también!

E: (RISAS)

B: ¡ME GUSTA MUY BIEN! (1’') eem ¡NO quiero casar un chico sinn castillo! // ¡ADIÓS! (RUIDO) ${ }^{65}$
A: [RISAS]
C: [RISAS]
D: [RISAS]
E: [RISAS]
F: [RISAS]

A: ¡ADIÓS CHICA!

[APLAUSOS]

\footnotetext{
${ }^{56} \mathrm{D}$ ofrece de nuevo otro vestido a $\mathrm{B}$.

${ }^{57}$ A realiza una pronunciación velar de la $\mathrm{r}$, con dificultades.

${ }^{58}$ A le indica a B en alemán cómo seguir la representación.

${ }^{59} \mathrm{El}$ profesor hace un chasquido para avisar de una nueva propuesta de entonación

${ }^{60} \mathrm{El}$ profesor hace un chasquido para avisar de una nueva propuesta de entonación

${ }^{61} \mathrm{El}$ profesor avisa a las vendedoras que la propuesta de entonación es para ellas.

${ }^{62} \mathrm{C}$ realiza la entonación de SORPRENDIDO que le habían propuesto.

${ }^{63} \mathrm{D}$ dice separarse en alemán y completa el enunciado en español de C.

${ }^{64}$ Entre risas.

${ }^{65} \mathrm{~B}$ tira el vestido que tenía en las manos al suelo.
} 